\title{
Principales manifestaciones causales de la presencia de rinofaringitis infantil
}

\section{Main causal manifestations of the presence of infantile rhinopharyngitis}

\section{Principais manifestações causais da presença de rinofaringite infantil}

\author{
Vanessa M. Cedeño-Zavalu ${ }^{\mathrm{I}}$ \\ vaneceza@yahoo.es \\ Carmen V. Arias-Nazareno II \\ victoriaa0110@gmail.com \\ Rita C. Barreto-Lopez III \\ ritabarreto65@hotmail.com
}

\author{
Mónica P. Mastarreno-Cedeño IV \\ monicamastarreno@gmail.com
}

Julio D. Cevallos-Villamar V julio-cevallos@hotmail.com

José F. Barreto-Loor VI fernando1984_loor@live.com

Correspondencia: vaneceza@yahoo.es

I. Doctor en Medicina y Cirugía; Médico Especialista en Alergia e Inmunología de la Asociacion de Alergia Asma e Inmunologia, Buenos Aires, Argentina.

II. Doctora en Medicina; Ministerio de Salud Pública, Docente en de la Universidad Estatal del Sur de Manabí, Manabí, Ecuador.

III. Licenciada en Enfermeria; Especialista en Enfermeria Nefrologica; Profesional en la Práctica Privada, Docente de la Universidad Estatal del Sur de Manabí, Manabí, Ecuador.

IV. Magíster en Docencia Universitaria; Licenciada en Enfermería; Docente en de la Universidad Estatal del Sur de Manabí, Manabí, Ecuador.

V. Médico Cirujano; Docente en de la Universidad Estatal del Sur de Manabí - Nivelación.

VI. Médico Cirujano; Médico General de primer nivel de atención 2 Ministerio de Salud Pública del Ecuador. 


\title{
Resumen
}

La faringitis aguda es un diagnóstico empleado muchas veces en el resfriado común, en su mayoría son víricas $y$, en ocasiones, presentan una clínica muy característica que permite un diagnóstico etiológico muy aproximado. La faringitis estreptocócica no supone más de un 15\% de los casos. El cuadro clínico no siempre permite una fácil diferenciación entre faringitis vírica y bacteriana. El diagnóstico de faringitis estreptocócica debería fundamentarse en técnicas de detección rápida de antígenos, no siempre disponibles en AP. En ausencia de las mismas, el pediatra deberá hacer una cuidadosa valoración clínica para utilizar adecuadamente los ATB, pese a lo cual cometerá muchos errores por exceso. La penicilina y la amoxicilina siguen siendo los antibióticos de primera elección. Las cefalosporinas deberían reservarse para las faringitis recurrentes y los macrólidos para los niños alérgicos a la penicilina.

Palabras claves: Faringitis; Faringitis vírica; Faringitis bacteriana; Faringitis recurrente; Pediatría.

\begin{abstract}
Pharyngitis is an overused diagnosis, frequently confounded with the common cold. Viruses are the more frequent etiologic agents, sometimes with a characteristic clinical picture which allows a probably specific etiologic diagnosis. Streptococcus is present in no more of $15 \%$ of pharyngitis. Differential diagnosis between viral and bacterial pharyngitis is difficult if based on clinical bases alone. Diagnosis of streptococcal pharyngitis would be ideally based on rapid antigenic detection in the throat, but this techniques are not yet avalaible in most pediatric primary care offices. Whitout them, pediatrician must do a careful clinical assessment to minimize inadequate use of antibiotics, but in this scenario, overrated diagnosis is unavoidable. Penicillin and amoxicillin are the first antibiotic choices. Cephalosporins should be used only in recurrent pharyngitis. Macrolides are the first choice in penicillin allergies.
\end{abstract}

Keys words: Acute pharyngitis; Viral pharyngitis; Bacterial pharyngitis; Recurrent pharyngitis; Pediatrics.

\section{Resumo.}

A faringite é um diagnóstico excessivo, freqüentemente confundido com o resfriado comum. Os vírus são os agentes etiológicos mais frequentes, por vezes com um quadro clínico característico que 
permite um diagnóstico etiológico provavelmente específico. Streptococcus está presente em não mais de $15 \%$ de faringite. O diagnóstico diferencial entre faringite viral e bacteriana é difícil se baseado apenas em bases clínicas. O diagnóstico da faringite estreptocócica seria idealmente baseado na detecção antigênica rápida na garganta, mas essas técnicas ainda não estão disponíveis na maioria dos consultórios de cuidados primários pediátricos. Para eles, o pediatra deve fazer uma avaliação clínica cuidadosa para minimizar o uso inadequado de antibióticos, mas, nesse cenário, o diagnóstico superestimado é inevitável. A penicilina e a amoxicilina são as primeiras escolhas de antibióticos. As cefalosporinas devem ser usadas apenas em faringite recorrente. Os macrolídeos são a primeira escolha em alergias à penicilina.

Palavras chaves: Faringite Aguda; Faringite Viral; Faringite Bacteriana; Faringite Recorrente; Pediatria.

\section{Introducción.}

La faringitis es la inflamación (incluyendo eritema, edema, exudado, enantema, úlceras y vesículas), generalmente debida a infección, de las membranas mucosas de la garganta. Menos frecuentemente, es debida a causas ambientales, antiguamente conocidas como faringitis “irritativas": tabaco, polución, alérgenos, cáusticos, alimentos o líquidos muy calientes. Contrariamente a la creencia popular, los líquidos fríos no producen faringitis irritativas ni predisponen a la infección. Al contrario, el frío moderado es un analgésico para el dolor de garganta, recomendación recibida con sorpresa y alguna prevención por parte de los padres. Es un diagnóstico sobreutilizado en AP, al catalogar así, en muchas ocasiones, un resfriado común, simplemente por la visualización de una faringe congestiva. Si bien, hay faringitis en cualquier infección de vías altas y en muchas de vías inferiores, nos referiremos a la "faringitis" sensu estricto, como la infección viral o bacteriana circunscrita a la faringe, y no a la hiperemia faríngea que se produce en el transcurso de un cuadro catarral vírico de vías altas (rinofaringitis aguda o resfriado común, gripe, laringitis) o 
Vanessa M. Cedeño-Zavalu; Carmen V. Arias-Nazareno; Rita C. Barreto-Lopez; Mónica P. Mastarreno-Cedeño; Julio D. Cevallos-Villamar; José F. Barreto-Loor

bajas (bronquiolitis, bronquitis). A efectos prácticos, es muy útil diferenciar las faringitis que se producen en cuadros con participación nasal, generalmente de etiología vírica, de las faringitis en las que no hay sintomatología nasal, en las que la etiología puede ser bacteriana (i Brú, 2017, pag. 385)

Las Enfermedades respiratorias agudas (IRA) son el principal motivo de consulta pediátrica, representando cerca del $50 \%$ de las consultas, de las que un $10 \%$ terminan necesitando una reevaluación médica durante la fase aguda de la enfermedad (Gómez \& Valente, pag. 12).

Se estima que en el Tercer Mundo ocurren entre 500 y 900 millones de episodios de IRA al año, lo que significa entre un 20 y un $40 \%$ del total de todas las hospitalizaciones y el $34 \%$ de las muertes de menores de 5 años (Gómez \& Valente, pag. 12). En el año 2007 en Ecuador la primera causa de morbilidad en niños son las Enfermedades Respiratorias Agudas ocupando una tasa de 14\% (1 703.803 Habitantes). En la provincia de Cotopaxi al igual que en la mayoría de las provincias del país se ratifica como primera causa de morbilidad las Enfermedades Respiratorias Agudas con una tasa de 11,23\% (44.997 habitantes) (Zabala Haro, 2010, pag. 8).

La infección respiratoria es un grave problema de salud pública en niños menores de 5 años en el mundo. Se diseñó un ensayo clínico, que comparó tratamiento convencional con tratamiento convencional más homeopático unicista, en niños de 6 meses a 5 años con resfriado común y se realizó seguimiento por 2 meses. En el primer episodio de resfriado, se encontró que el grupo de homeopatía tuvo una recuperación más rápida, presentó menor duración de la rinorrea y menor intensidad. Durante el seguimiento fue menor la duración de la obstrucción nasal y su intensidad así como se observó mayores cambios positivos en el carácter y en el desempeño diarios Se concluye que la homeopatía usada adecuadamente, presenta resultados favorables en el tratamiento integral de niños con infección respiratoria aguda (Mora \& Cristina, 2012). 
Etiología

La mayor parte de faringitis son víricas, pese a lo cual se sigue tratando frecuentemente esta enfermedad con antibióticos. El estreptococo pyogenes es el principal agente bacteriano causante de faringitis bacteriana primaria en Pediatría. La mayor parte de faringitis son víricas (65-80\%) y tienen un predominio estacional (otoño-invierno-primavera). El estreptococo beta hemolítico del grupo A (EBHGA, estreptococo pyogenes) es el agente bacteriano predominante; si bien, salvo en periodos epidémicos, en los que puede ser causa de un 30\% de episodios, no origina más de un $15 \%$ del total de infecciones, predominando al final del invierno y principio de primavera (i Brú, 2017, pag. 386).

Se caracteriza por producir una hemólisis clara en agar sangre (hemólisis beta), rasgo bacteriológico muy importante para diferenciarlo de los estreptococos que no producen hemólisis (gamma) y de los que producen hemólisis parcial (alfa o viridans, neumococo...). Los estreptococos betahemolíticos de los grupos $\mathrm{C}$ (especialmente, estreptococo equisimilis) y $\mathrm{G}$, pueden causar un cuadro clínico semejante al EBHGA, posiblemente subvalorado en su frecuencia, dado que los test de diagnóstico rápido (TDR) no los detectan. $\mathrm{El}$ estreptococo del grupo $\mathrm{C}$ se ha relacionado con epidemias de faringitis en universitarios y adultos jóvenes, y en epidemias transmitidas por vía alimentaria (i Brú, 2017, pag. 386).

No se ha descrito fiebre reumática asociada a estos grupos, aunque sí algún caso de glomerulonefritis. Muchos otros agentes bacterianos se han relacionado con la faringitis, pero solo Mycoplasma pneumoniae y posiblemente Chlamydea pneumoniae parecen tener algún papel secundario como agentes etiológicos en faringitis pediátrica, especialmente en casos recurrentes. Arcanobacterium hemolíticum es responsable de una forma de faringitis frecuentemente asociada a 
Vanessa M. Cedeño-Zavalu; Carmen V. Arias-Nazareno; Rita C. Barreto-Lopez; Mónica P. Mastarreno-Cedeño; Julio D. Cevallos-Villamar; José F. Barreto-Loor

exantema escarlatiniforme, que se presenta en adolescentes y responde a macrólidos (i Brú, 2017, pag. 386).

Si bien, es frecuente el aislamiento en faringe de neumococo, Hemophillus influenza y estafilococo, no está establecido su papel como agentes etiológicos en faringitis. Neisseria gonorrheae puede ser raramente causa de faringitis en adolescentes sexualmente activos y en niños sometidos a abuso sexual. La difteria es una enfermedad olvidada en nuestro medio que puede causar una faringitis membranosa semejante a la estreptocócica o a la mononucleosis infecciosa (i Brú, 2017, pag. 386).

\section{Desarrollo.}

Cada día adquiere mayor importancia el conocimiento que deben poseer los profesionales de la salud y las comunidades en general sobre los diferentes factores de riesgo que de una u otra forma afectan nuestra salud, pero principalmente en edades pediátricas, es por ello que en el presente trabajo se aborda fundamentalmente las principales infecciones respiratorias agudas en menores de 5 años, así como sus factores de riesgos clínico epidemiológicos que influyeron en su aparición. Partiendo del criterio que hay que tener en cuenta, que las infecciones respiratorias agudas constituyen la primera causa de consulta y hospitalización en edades pediátricas. Estudios internacionales han demostrado que el número de episodios anuales de infecciones respiratorias agudas en niños menores de 5 años, y los agentes etiológicos involucrados son similares en países desarrollados y en vías de desarrollo. De los grandes problemas que afectan a nuestra infancia, las infecciones respiratorias agudas (IRA), ocupan un papel predominante en cuanto a morbilidad se refiere (Barcelos Arellane \& Barrios Zaragoza, 2014). 
El conocimiento de los factores de riesgo en las infecciones respiratorias agudas como en otras enfermedades, parten del enfoque general que hay que tener de riesgo para poder comprender la relación causa efecto, por lo que se define como factor de riesgo a un predictor estadístico de la enfermedad. Podría conceptualizarse, como aquella circunstancia, hallazgo personal o ambiental que se relaciona estadísticamente con la enfermedad. Para poder considerarlos como tales deben cumplirse una serie de requisitos como son: la presencia previa del factor a la enfermedad y su asociación consistente con la enfermedad, entre otros Se han identificado un número de factores predisponentes o de riesgo, los que pueden agruparse de acuerdo a su relación con el huésped, el medio ambiente que lo rodea y el agente infeccioso. En la mayoría de los niños con infecciones respiratorias agudas pueden encontrarse más de un factor de riesgo, siendo los factores socioeconómicos el denominador común que favorece el bajo peso al nacer, la desnutrición, la falta de inmunizaciones y las condiciones ambientales desfavorables (Barcelos Arellane \& Barrios Zaragoza, 2014).

El conocimiento de estos factores de riesgo es muy importante tanto para la prevención como el seguimiento de los niños en riesgo. La OMS en los últimos años ha apoyado el programa de control de IRA en el que uno de sus pilares fundamentales lo constituye el manejo estándar de casos, que destaca que por su etiología y evolución en la mayoría de los casos, resulta innecesario y hasta perjudicial el uso de productos aparentemente destinados a mejorar los síntomas, y más aún el uso indiscriminado de antibióticos (Barcelos Arellane \& Barrios Zaragoza, 2014).

Resfriado Común (Rinofaringitis Aguda) El resfriado común es una enfermedad viral aguda, autolimitada, de carácter benigno, transmisible llamado también «catarro común», «resfrío», «rinofaringitis» o «nasofaringitis», aunque en algunos casos estos términos resultan inapropiados 
Vanessa M. Cedeño-Zavalu; Carmen V. Arias-Nazareno; Rita C. Barreto-Lopez; Mónica P. Mastarreno-Cedeño; Julio D. Cevallos-Villamar; José F. Barreto-Loor

pues no siempre el resfriado común compromete la faringe; mal llamada "gripa", constituye 50\% de las infecciones de las vías respiratorias superiores (Rodríguez, Caicedo, \& Garcia, 2009, pag. 18)

Cuadro clínico Después de un periodo de incubación que varía de dos a cinco días, aparecen los síntomas predominantes del resfriado común como rinorrea, obstrucción nasal y estornudos. Otros síntomas son: tos, dolor de garganta, cefalea y malestar general; la fiebre varía en intensidad y frecuencia; puede haber sintomatología en otros sistemas como vómitos, diarrea, dolor abdominal, mialgias e irritación ocular (Rodríguez, Caicedo, \& Garcia, 2009, pag. 18).

Se caracteriza por diferentes grados de manifestaciones, dependiendo de la edad del paciente. En los menores de tres meses la coriza es el único síntoma y la fiebre es rara o discreta. En los lactantes mayores de tres meses, quienes generalmente tienen fiebre, irritabilidad y en cuanto más pequeño es el niño más manifiesta es la obstrucción nasal que interfiere con la alimentación o el sueño (Rodríguez, Caicedo, \& Garcia, 2009, pag. 18).

En los niños mayores al igual que en los adultos, el inicio de la enfermedad se caracteriza, en $80 \%$ de las veces, por la presencia de malestar general, cefalea, ardor de garganta, tos, irritación nasal y escurrimiento nasal posterior (Rodríguez, Caicedo, \& Garcia, 2009, pag. 18)

La faringitis es una enfermedad en la que se produce una inflamación en la garganta, concretamente en la faringe. Se inflama la mucosa que recubre las paredes de esta parte del cuerpo humano. Normalmente, se trata de una enfermedad de origen vírico, aunque es posible que existan algunos casos en los que el origen sea bacteriano. Aparte del dolor que produce en la garganta, también es posible que exista dolor de cabeza y fiebre (Benito Cabrera, 2016). 
La aparición de los virus en la faringe hará que ésta se inflame y empiece el dolor de garganta. Hay factores que favorecen la aparición de esta afección en los niños: vivir en un lugar en el que el aire que se respira esté altamente contaminado, estar en contacto con el humo del tabaco de los adultos fumadores, alergias y el aire acondicionado (Benito Cabrera, 2016).

La faringitis es una de las causas más comunes para que los niños sean llevados al médico, sobre todo en dos épocas del año: invierno y primavera. Se produce en estas épocas del año por ser las que más cambios de temperatura presentan. La presentación de esta enfermedad en los niños comúnmente viene precedida de una gripe que hace que los virus inflamen la faringe (Benito Cabrera, 2016).

\section{Metodología.}

La investigación que aquí se presenta es de tipo documental y bibliográfica, toda la información obtenida, está disponible en diferentes medios electrónicos de consulta pública, aquí se ha reflejado una revisión bibliográfica del tema en estudio.

\section{Resultados.}

\section{Sintomas de la faringitis}

La faringitis tiene unos síntomas que podemos confundir con otros episodios infecciosos, aun así es importante tener presente cuáles son y cómo se presentan:

1. Dolor de garganta. Éste es uno de los principales síntomas de la faringitis. Al inflamarse la faringe, se produce un gran dolor en la garganta del niño por ejemplo a la hora de 
Vanessa M. Cedeño-Zavalu; Carmen V. Arias-Nazareno; Rita C. Barreto-Lopez; Mónica P. Mastarreno-Cedeño; Julio D. Cevallos-Villamar; José F. Barreto-Loor

tragar. Esto se produce por la irritación que se produce en las paredes de esta parte del cuerpo.

2. Fiebre. Los virus que hacen que la faringe se inflame, también provocan que la temperatura corporal de los niños enfermos aumento. Además, la fiebre a menudo suele ir acompañada de escalofríos y dolores de cabeza provocados por el aumento de la temperatura corporal.

3. Tos. Este síntoma se produce porque el organismo de los niños nota la presencia de mucosidad en las vías respiratorias y busca expulsarla para que éstas queden despejada y hacer que la persona que esté enferma pueda respirar con mayor facilidad.

4. Dolor de cuerpo. Este síntoma es una consecuencia del resto de los síntomas. El dolor de garganta, la tos y la fiebre pueden crear un malestar general en el cuerpo de los niños que llegue a provocarles un dolor general que suponga una continua molestia para ellos.

5. Sequedad de la garganta. La presencia de la tos y la mucosa harán que sea necesaria una hidratación mayor para poder aliviar la irritación provocada por la sequedad que crean estos dos síntomas.

6. Falta de apetito. Realmente, no se trata de una falta de apetito por falta de hambre. En verdad, la falta de apetito se deriva del malestar general y de los dolores en la garganta a la hora de ingerir alimento alguno o simple saliva.

Los síntomas pueden presentarse todos o algunos. Los comunes son aquellos referidos a la irritación y dolor de la garganta. La fiebre puede aparecer o no dependiendo la gravedad de la faringitis (Benito Cabrera, 2016).

Tratamiento de la faringitis en niños 
Antes de tomar cualquier tipo de decisión sobre el diagnóstico y futuro tratamiento de un niño habrá que tener claro que realmente tiene faringitis, no guiarnos únicamente por los síntomas. En cualquier caso, si los síntomas como el dolor de garganta persisten más allá de las 24 horas y la fiebre no baja será recomendable acudir al médico. También hay otros remedios que no tienen nada que ver con la medicina que pueden incluirse para complementar el tratamiento puesto por el médico.

- Medicamentos. Opciones como el ibuprofeno o el parecetamol son recetadas para acabar con el dolor, la inflamación y la fiebre. En los casos más graves y dependiendo del origen de la faringitis, ya sea vírica o bacteriana, pueden ser recetados antibióticos. Además, también están los mucolíticos que ayudarán a que la mucosa presente en las paredes de la faringe desaparezca. Antes de tomar cualquier tipo de medicamento hay que prestar atención a las posibles alergias.

- Descanso. Aunque sea algo común, para que el niño pueda reponer fuerzas y encontrarse mejor deberá guardar reposo. Además, la fiebre en algunos casos puede producir mareos, por lo que no será muy recomendable mucho movimiento para el niño.

- Hidratación. Como ya hemos dicho en los síntomas, la zona de la garganta padece una gran sequedad por la inflamación de las paredes mucosas de la faringe y la tos. Por ello, será recomendable ingerir una mayor cantidad de agua para poder contrarrestar este efecto de la faringitis.

- Gárgaras. Pueden hacerse con suero o con agua con sal. Ambos líquidos servirán para acabar con la irritación de la garganta y así aliviar uno de los síntomas más molestos ya que provoca un dolor ya sea al tragar comida o simple saliva. 
Vanessa M. Cedeño-Zavalu; Carmen V. Arias-Nazareno; Rita C. Barreto-Lopez; Mónica P. Mastarreno-Cedeño; Julio D. Cevallos-Villamar; José F. Barreto-Loor

- Humidificador de aire. Este utensilio doméstico ayuda a que el aire que rodea al enfermo tenga una mayor humedad. Esto ayudará a que la sequedad de la garganta se alivie y el dolor disminuya (Benito Cabrera, 2016).

\section{Faringoamigdalitis}

La faringoamigdalitis aguda o faringoamigdalitis como entidad aislada es una de las enfermedades más comúnmente vista por los médicos generales y pediatras en consulta. Es una inflamación de las estructuras mucosas y submucosas de la garganta. La faringe es la cavidad común de los tractos respiratorio y digestivo. Está compuesta por la nasofaringe, que contiene las amígdalas faríngeas (adenoides) en su pared posterior; las amígdalas tubáricas, detrás del orificio de la trompa auditiva; la orofaringe, que contiene las amígdalas palatinas (fauciales) en su parte baja y en el tercio posterior de la lengua, las amígdalas linguales que vienen a constituir el anillo amigdalar de Waldeyer (Zabala Haro, 2010, pag. 14).

Estas estructuras tienen una predisposición aumentada a la inflamación e infección por su abundante contenido de tejido linfoide y además una característica especial en la infancia como órgano de crecimiento y en su papel inmunológico. En cuanto a su patrón de crecimiento, entre las edades de cuatro a 10 años, alcanza su máximo tamaño, lo cual es importante tener claro en pediatría y no considerar unas amígdalas grandes o un tejido adenoideo crecido como un crecimiento patológico que justifique tratamiento con antibióticos o conducta quirúrgica. En cuanto a su papel inmunológico a este nivel se produce $\operatorname{IgA}$ secretora que reacciona a infecciones y ante agresiones alérgicas, produciendo aumento de tamaño que tampoco requiere dicho tratamiento (Zabala Haro, 2010, pag. 14)

Factores epidemiológicos 
La mayoría de los casos de faringoamigdalitis aguda ocurre durante los meses más fríos y lluviosos en países con estaciones. Es así como las infecciones por estreptococos usualmente aparecen en el invierno tardío o en la primavera temprana

Siendo el hábitat natural para la mayor parte de los estreptococos del grupo A el tejido linfoide de la orofaringe, la transmisión ocurre en epidemias y en lugares de elevado hacinamiento donde sube la frecuencia a $80 \%$. De igual manera es frecuente que el pico de infección se aumente cuando el niño comienza a asistir a la escuela (son los niños que tienen alrededor de tres años de edad).

Alrededor de los seis meses de edad la inmunidad transmitida por la madre se reduce dramáticamente y los lactantes se hacen más susceptibles a las infecciones del tracto respiratorio superior.

El riesgo de contagiarse de un niño es cerca de 20 a 50\% dependiendo de la virulencia del germen y del grado de hacinamiento (Zabala Haro, 2010, pag. 15).

\section{Faringitis víricas}

La faringitis vírica inespecífica es aquella en la que la clínica no permite orientar el diagnóstico etiológico. Observamos una faringe hiperémica y nada más. Suele tener un inicio gradual, con: fiebre moderada o ausente, faringodinia, tos irritativa de intensidad variable, pequeñas adenopatías y poca afectación del estado general. El examen de la faringe muestra hiperemia variable. El cuadro suele resolverse en 3-6 días. Puede observarse que en niños de menos de 2 años (menos de 18 meses si asisten a guardería, lo que aumenta la probabilidad de infección por EBHGA) 
Vanessa M. Cedeño-Zavalu; Carmen V. Arias-Nazareno; Rita C. Barreto-Lopez; Mónica P. Mastarreno-Cedeño; Julio D. Cevallos-Villamar; José F. Barreto-Loor

es muy sugestivo de infección por adenovirus. Puede acompañarse de exantema inespecífico, cuadro catarral y sintomatología digestiva (i Brú, 2017, pag. 386).

El adenovirus también puede causar una faringitis nodular.

- La fiebre faringoconjuntival es otra expresión clínica de la infección por adenovirus, especialmente del tipo 3, que asocia marcada hiperemia faríngea con conjuntivitis no purulenta. Es frecuente la palpación de adenopatía preauricular. La fiebre puede durar hasta 7 días y la conjuntivitis hasta 14. Se han descrito epidemias transmitidas en piscinas, por inoculación conjuntival a partir de agua contaminada. Las faringitis por adenovirus pueden ser confirmadas en la consulta en 15 minutos con un test de inmunocromatografía que detecta el antígeno a partir de una muestra de moco obtenida por lavado y aspirado nasal o por frotis nasofaríngeo, que puede formar parte de kits diagnósticos multivíricos con gripe y VRS.

- La herpangina es una infección por enterovirus coxsackie A (6 y 16) y B y, menos frecuentemente, por enterovirus 71 , echovirus y virus del herpes simple, que se caracteriza por la aparición de vesículas de 1-2 mm que posteriormente se ulceran, que se circunscriben a la faringe posterior sin rebasar los pilares anteriores amigdalinos, con lo que hacemos el diagnóstico diferencial con la infección herpética. El niño puede sufrir ataques recurrentes. Las infecciones por enterovirus son más frecuentes en verano y principio de otoño.

La fiebre faringonodular, también causada por coxsackie, se caracteriza por pequeños nódulos, no ulcerativos, de color blanco o amarillento, que tienen la misma distribución que la herpangina, pero es mucho menos frecuente. 
El cuadro dura 1-2 semanas

- La enfermedad boca-mano-pie (coxsackie A 16 y enterovirus 71) se caracteriza por fiebre y pequeñas úlceras en lengua y mucosa bucal, acompañadas por máculas o vesículas que no ulceran en palmas de las manos, plantas de los pies y espacios interdigitales. Pueden observarse ocasionalmente lesiones en tronco y extremidades. Las formas por enterovirus son mucho más graves, con potencial afectación neurológica. Después de unas semanas o meses puede observarse onicomadesis reversible en manos y pies, posibilidad de la que hay que advertir a la familia.

- La primoinfección herpética suele manifestarse con un cuadro febril acompañado de gingivoestomatitis, con vesículas que rápidamente ulceran, que afectan al paladar duro y a las encías, pero en fases iniciales puede confundirse con una faringitis vírica.

- La mononucleosis infecciosa cursa con amigdalitis exudativa. En ocasiones, la hipertrofia amigdalar es tan severa que causa obstrucción respiratoria y requiere de tratamiento con corticoides e incluso de cirugía. Puede observarse edema preesternal o periorbital. Las adenopatías son muy marcadas y puede palparse esplenomegalia. En niños pequeños, el cuadro es atípico y debe sospecharse ante toda faringitis exudativa que no responda al tratamiento antibiótico. En la actualidad, puede confirmarse en la consulta con un TDR inmunocromatográfico que detecta en 5 minutos anticuerpos heterófilos en sangre capilar, pero que puede ser negativo en menores de 5 años, en los que el diagnóstico se hará con la detección de anticuerpos contra el antígeno de la cápside viral (VCA), que aparecen más precozmente que los dirigidos contra los antígenos del núcleo. 
Vanessa M. Cedeño-Zavalu; Carmen V. Arias-Nazareno; Rita C. Barreto-Lopez; Mónica P. Mastarreno-Cedeño; Julio D. Cevallos-Villamar; José F. Barreto-Loor

- Pese a su rareza, no debemos olvidar que la infección aguda por el VIH (síndrome retroviral agudo) puede manifestarse como una faringitis no exudativa, con: fiebre, linfadenopatía, artralgias, mialgias, letargia y exantema maculopapular. El tratamiento de la faringitis vírica es sintomático. El dolor de garganta puede tratarse con paracetamol o ibuprofeno. En caso de faringodinias muy intensas que no cedan a la analgesia habitual, es muy útil una tanda corta de corticoides orales.

Algunos niños mayores experimentan mejoría chupando pastillas "antisépticas", de las que hay una amplia gama en el mercado OTC y que suelen tener en su composición algún antiinflamatorio local (bencidamida). Los gargarismos de tomillo son un remedio casero tan olvidado como excelente.

\section{Faringitis bacterianas}

La faringitis estreptocócica es la causa más frecuente de faringitis bacteriana, pero no causa más de un $15 \%$ de todos los casos de fiebre y dolor de garganta. El principal factor de virulencia es la proteína M de superficie, que dificulta la opsonofagocitosis y condiciona la existencia de distintos serotipos, con variable tropismo tisular.

Hay 220 tipos de proteína M, que generan inmunidad tipo específica, lo que explica el carácter repetitivo de las infecciones. Los tipos $\mathrm{M}$ causantes de faringitis rara vez dan infecciones cutáneas y viceversa. Después de la infección se desarrolla inmunidad específica de serotipo M, pero no inmunidad cruzada con otros serotipos.

El EBHGA (estreptococo pyogenes) tiene amplia expresividad clínica. Los cuadros más frecuentes son: faringitis, impétigo (cepas potencialmente nefritógenas, pero no reumatógenas), 
escarlatina, celulitis y celulitis perianal. Menos frecuentes son: vulvovaginitis, neumonía, artritis séptica, osteomielitis, meningitis y fascitis necrotizante, de la que aumentan los casos como complicación de la varicela tratada con ibuprofeno (una asociación no determinada aún como causal). No hay que olvidar las secuelas no supurativas (fiebre reumática y glomerulonefritis). El EBHGA puede estar presente asintomáticamente en faringe (estado de portador), recto y vagina en $10-15 \%$ de niños en edad escolar, pero en periodos epidémicos hasta un $50 \%$ de niños pueden estar colonizados. Estos niños no desarrollan respuesta inmunitaria ni tienen riesgo de presentar fiebre reumática o glomerulonefritis. Su capacidad de transmisión es baja. La faringitis por EBHGA tiene un periodo de incubación de 2-5 días y un inicio brusco, con fiebre alta, frecuentemente superior a $39^{\circ} \mathrm{C}$ (i Brú, 2017, pag. 386-387).

Imagen 1. Complicaciones de las Faringitis Baterianas

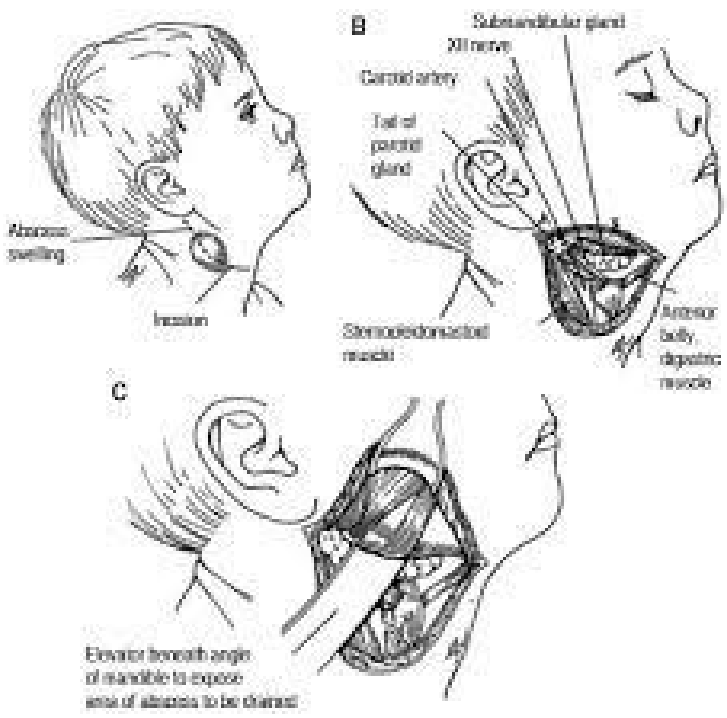


Fuente: (Cuestas, y otros, 2014)

La faringodinia es intensa y puede preceder a la aparición de la fiebre y de los signos inflamatorios faríngeos, lo que dificulta enormemente el diagnóstico, pero tiene un alto valor predictivo en niños con faringitis estreptocócica recurrente. Las adenopatías tonsilares pueden ser de gran tamaño. El niño puede estar prostrado, con cefalea, vómitos y, en ocasiones, meningismo. No es excepcional la presencia de un dolor abdominal intenso, por adenitis mesentérica, que plantee dudas diagnósticas con el abdomen agudo e incluso provoque apendicectomías blancas.

La faringe suele presentar marcada hiperemia, con afectación variable de las amígdalas, que frecuentemente presentan un exudado blanquecino, que no es patognomónico de infección bacteriana.

Es frecuente que la úvula participe de la inflamación. Sin embargo, la presencia de una uvulitis circunscrita, con gran tumefacción, fiebre alta y mal estado general, en niños de menos de 3 años no correctamente inmunizados, debe hacernos sospechar la posibilidad de infección por Hemophillus influenza invasivo (Hib), y derivar al niño al hospital para descartar meningitis.

En la actualidad en nuestro medio, con coberturas vacunales frente a Hib casi universales, una uvulitis con buen estado general es muy sugestiva de infección estreptocócica. La presencia de petequias en paladar blando y/o úvula es también muy sugestiva, pero no patognomónica de infección estreptocócica. Debe valorarse toda la clínica en su contexto, puesto que es sorprendente la gran disociación que puede haber entre el aspecto de la faringe y la etiología de la enfermedad (i Brú, 2017, pag. 387). 
Estas infecciones, que en su mayoría tienen evolución favorable, ayudan a desarrollar el sistema inmunológico de los niños, aunque para la familia representan motivo de preocupación y ansiedad, sobre todo, cuando son recurrentes. Un paciente tiene infecciones recurrentes cuando presenta una mayor frecuencia de infecciones que las correspondientes para su edad y medio ambiente. El número de infecciones no establece diferencias entre el desarrollo inmune normal y las causas predisponentes o inmunodeficiencias, de modo que es fundamental la historia clínica y el examen físico completo que orienten el diagnóstico y estudio de cada paciente. En muchos niños, la repetición de estos procesos no es más que una manifestación de la atopia. Para algunos autores, los niños presentan entre 7 y 10 episodios de IRA por año, que son en su mayoría, leves y autolimitados, pero representan un trabajo enorme para los servicios de salud. Un grupo de niños, especialmente los que poseen factores de riesgo, pueden Infecciones respiratorias altas recurrentes. Algunas consideraciones cursar hacia una neumonía o una enfermedad más grave, la cual aumenta la posibilidad de muerte y requiere atención hospitalaria. Dentro de este grupo nosológico de IRA tenemos:

\section{Rinofaringitis}

- Otitis media aguda.

- Amigdalitis y Faringoamigdalitis.

- Rinosinusitis.

- Adenoiditis.

- Sinusitis.

Sin embargo, se debe tener presente que muchas enfermedades respiratorias afectan tanto el tracto superior como el inferior en forma concomitante o secuencial. Es fundamental conocer su 
Vanessa M. Cedeño-Zavalu; Carmen V. Arias-Nazareno; Rita C. Barreto-Lopez; Mónica P. Mastarreno-Cedeño; Julio D. Cevallos-Villamar; José F. Barreto-Loor

etiología, patogenia y evolución, para poder formular un diagnóstico correcto que permita, a su vez, un tratamiento concordante. A pesar de constituir motivo de consulta tan frecuente, existe una gran variedad de tratamientos, no acordes con su etiología y evolución. Se plantea que la aparición de episodios de IRA en niños pequeños, es independiente de las condiciones de vida donde se desenvuelve y del grado de desarrollo del país de procedencia.

La diferencia entre países desarrollados y en vías de desarrollo no se encuentra en el número de episodios, sino en su gravedad y el mayor riesgo de adquirir neumonía y morir en el curso de una IRA (Abreu SG. Factores de riesgo en las infecciones respiratorias agudas [IRA]. Curso respiratorio. Hospital Pediátrico de Centro Habana, 2006) (Álvarez Castelló, y otros, 2008).

\section{Otras formas clínicas de faringitis}

- Arcanobacterium hemolíticum es causa de faringitis en niños mayores de 10 años. Es especialmente frecuente entre los 15-18 años, franja etaria en la que puede suponer el 2,5\% de todos los casos. Cursa con una faringitis exudativa similar a la estreptocócica. En el 50\% de casos presenta un rash escarlatiniforme. Desde el punto de vista práctico, la presencia de faringitis y un exantema sugestivo de escarlatina, en un niño mayor de 10 años, debe hacernos sospechar esta etiología y tratar el caso con un macrólido, puesto que este gérmen no responde a la penicilina.

Si no hemos descartado EBHGA con la práctica de un test rápido o cultivo, el macrólido debería ser de 16 átomos (josamicina), para cubrir adecuadamente ambos gérmenes, dado que hasta un $20 \%$ de EBHGA en nuestro medio son resistentes a macrólidos de 14 (eritromicina, claritromicina) y 15 átomos (azitromicina). 
- Síndrome de Lemierre: rara complicación de la faringitis causada por Fusobacterium necrophorum, consistente en trombof lebitis de la vena yugular.

Sin embargo, la infección por fusobacterium puede suponer hasta un $10 \%$ de faringitis en adolescentes y adultos jóvenes y, generalmente, cursa con clínica leve e indistinguible de la faringitis estreptocócica(5). En ocasiones, puede ser muy grave con cuadro séptico y disnea debida a émbolos sépticos pulmonares.

- Síndrome PFAPA: acrónimo inglés de fiebre periódica, estomatitis aftosa, faringitis y adenopatías. Es un cuadro recurrente, no excepcional si se piensa en él, de causa desconocida, posiblemente infecciosa. Es más frecuente en menores de 5 años. No responde a antibióticos. Se han comunicado buenos resultados con corticoides ( 1 o 2 dosis de prednisona) y con cimetidina. La amigdalectomía ofrece buenos resultados en la prevención de las recurrencias.

- Escarlatina: en la actualidad, se presenta con clínica poco florida, incluso, en ocasiones, sin fiebre. Estos exantemas escarlatiniformes con clínica atípica presentan frecuentemente frotis faríngeo positivo, por lo que en ausencia de pruebas objetivas, se recomienda su tratamiento específico.

Es producida por la toxina pirogénica (anteriormente conocida como eritrogénica) del EBHGA, de la que existen 3 clases: A (la más frecuente), B y C, con desarrollo de inmunidad específica. Un niño puede presentar, por tanto, diversos episodios de escarlatina. Es rara en lactantes, probablemente por la acción protectora de anticuerpos transplacentarios contra la toxina pirogénica (i Brú, 2017, pag. 388).

\section{Complicaciones}


Vanessa M. Cedeño-Zavalu; Carmen V. Arias-Nazareno; Rita C. Barreto-Lopez; Mónica P. Mastarreno-Cedeño; Julio D. Cevallos-Villamar; José F. Barreto-Loor

Se observa actualmente un aumento de la frecuencia de las mismas, o bien por un cambio en la agresividad del EBHGA o, posiblemente, por la reducción del tratamiento antibiótico de las faringitis. Disminuyeron radicalmente con la generalización de los antibióticos, pero en la actualidad, estamos asistiendo a un aumento de las mismas.

- Absceso periamigdalino: generalmente producido por EBHGA y, más raramente, por estreptococo alfa-hemolítico y del grupo D, neumococo y anaerobios. La amígdala afectada protruye medialmente y el pilar anterior amigdalino se desplaza hacia delante. Hay desplazamiento de la úvula y el paladar blando. Si no se trata puede evolucionar hacia el absceso faríngeo lateral que puede comprometer la vía aérea y erosionar la arteria carótida. Debe derivarse el niño al hospital para recibir tratamiento endovenoso. Es más frecuente en adolescentes y adultos jóvenes.

- Absceso retrofaríngeo: generalmente producido por EBHGA y, más raramente, por estafilococo. El niño se presenta con hiperextensión del cuello, disfagia, salivación y disnea. Puede parecer un crup. La visualización de la faringe muestra tumoración faríngea posterior unilateral en menos del $50 \%$ de casos. El niño debe ser derivado para recibir tratamiento endovenoso y, en ocasiones, desbridamiento quirúrgico. Puede resolverse sin cirugía en un $50 \%$ de casos. Afecta más a niños menores de 4 años.

- Complicaciones supurativas: la otitis media y la adenitis cervical son relativamente frecuentes. La celulitis es más rara. La septicemia es excepcional (i Brú, 2017, pag. 388).

\section{La diferenciación entre faringitis bacteriana y faringitis vírica es compleja}

La valoración conjunta y cuidadosa de toda la sintomatología y semiología descrita anteriormente, aun hecha por un pediatra experimentado, tiene una correlación muy pobre con la 
confirmación microbiológica. La faringitis estreptocócica se ha considerado, clásicamente, rara antes de los 3 años y excepcional antes del año. Sin embargo, en niños que asisten a guardería, puede presentarse a partir de los 18 meses, especialmente en brotes epidémicos. En la actualidad, parece desplazarse hacia edades más precoces.

No es excepcional la infección estreptocócica del niño pequeño e incluso del lactante, que no se manifiesta en forma de faringitis sino de un cuadro llamado fiebre estreptocócica infantil o estreptococosis, de difícil reconocimiento, que se manifiesta en el niño de menos de 6 meses por fiebre inferior a $39^{\circ} \mathrm{C}$, hiperemia faríngea y rinorrea mucoserosa, con impetiginización de las narinas, que se diagnostica habitualmente como resfriado común, y en el niño de 6 meses a 3 años con fiebre inferior a $39,5^{\circ} \mathrm{C}$, rinorrea, hiperemia faríngea y mayor afectación del estado general, con vómitos, anorexia y adenopatías, cuadro que se presenta con carácter intermitente durante 4-8 semanas.

Se han propuesto muchas escalas clínicas para la valoración adecuada de la etiología de la faringitis, pero ninguna ha mostrado suficiente sensibilidad-especificidad para la toma de decisiones. La más prestigiosa es la escala de Centor, diseñada para adultos y adaptada a la edad pediátrica por Mc Isaac. Otorga un punto a cada uno de los siguientes signos: temperatura superior a $38^{\circ} \mathrm{C}$, ausencia de tos, adenopatías dolorosas, exudado y edad entre 3-14 años. Se considera sugestiva de infección bacteriana una puntuación igual o superior a 3, pero muchos test de diagnóstico rápido (TDR) positivos cursan con puntuaciones más bajas. Además, puntuaciones superiores a 4, cursan con la presencia de EBHGA solo en un $70 \%$ de casos.

En nuestra opinión, esta escala presenta muchas debilidades: procede de un estudio para adultos, es antigua, puntúa la ausencia de tos (síntoma muy frecuente en faringitis estreptocócica si 
Vanessa M. Cedeño-Zavalu; Carmen V. Arias-Nazareno; Rita C. Barreto-Lopez; Mónica P. Mastarreno-Cedeño; Julio D. Cevallos-Villamar; José F. Barreto-Loor

se indaga por él, pero no manifestado frecuentemente como motivo de consulta, que suele ser la fiebre y/o el dolor de garganta) y no valora signos tan predictivos como la uvulitis o la escarlatina). Creemos que no es suficientemente sensible ni específica para decidir hacer o no un TDR, pero puede ser útil en ausencia de test diagnósticos (i Brú, 2017, pag. 389).

\section{Otitis media aguda}

La otitis media aguda es una de las causas más frecuentes de consulta pediátrica. Teel y colaboradores reportaron que $62 \%$ de los niños de un año han tenido por lo menos un episodio; este porcentaje se elevó a $83 \%$ a la edad de tres años y a los siete años todos los niños habían tenido un episodio de otitis aguda. Por el contrario, es una entidad de rara ocurrencia en adultos. En una revisión de 17.000 visitas durante el primer año de vida, la otitis media aguda fue el diagnóstico en $1 / 3$ de los casos que consultaron por enfermedad y en $1 / 5$ del total de controles en salud. La prevalencia es máxima entre los seis y 13 meses de vida con un segundo pico a los cinco o seis años, coincidiendo con el ingreso escolar (Rodríguez, Caicedo, \& Garcia, 2009, pag. 29-30)

\section{Diagnóstico}

Las manifestaciones clínicas más comunes de la otitis media son rinitis, tos, astenia, irritabilidad, fiebre y otalgia, tal como lo reveló un estudio clínico de 363 niños con otitis media aguda, en el que se encontraron los siguientes porcentajes En los lactantes menores de seis meses el cuadro puede ser más inespecífico: fiebre, irritabilidad, vómito, apatía, anorexia, diarrea.

\section{Métodos diagnósticos}

Frente a un cuadro clínico sospechoso, la otoscopia convencional sigue siendo el método diagnóstico de elección. Es aconsejable un otoscopio de luz halógena, con baterías nuevas, así como 
un conducto libre de cerumen para visualizar el tímpano. Este procedimiento puede ser difícil en el niño, por el tamaño reducido del conducto auditivo externo y por las características propias de sujeción de los pequeños.

A un grupo de médicos de nueve países se les indagó acerca de qué tan certeros eran en el diagnóstico de otitis media en niños pequeños. Se encontró únicamente $58 \%$ de aciertos en el grupo de 0-12 meses; 66\% en el grupo de 13-30 meses y 73\% en mayores de 30 meses de edad.

Esto demuestra la dificultad en el diagnóstico de la otitis media en el niño pequeño. El enrojecimiento del tímpano únicamente, sin datos de abombamiento, opacidad o distensión, no se relaciona bien con otitis media aguda y puede deberse al llanto, intento de remover el cerumen o cuadros virales de vías respiratorias altas.

La otoscopia neumática (perilla neumática instalada en el otoscopio), que efectúa presión positiva y negativa al tímpano, es un método bastante útil, ya que se comprueba la escasa movilidad de la membrana ante la presencia de líquido o pus (Rodríguez, Caicedo, \& Garcia, 2009, pag. 3031).

\section{Conclusiones.}

No puede concluirse un capítulo de faringitis sin referirse a la amigdalectomía. Las indicaciones actuales se han reducido a casos de hipertrofia severa que dificulte la respiración (causa fundamental de la apnea obstructiva del sueño que, en la actualidad, puede confirmarse con estudios de polisomnografía), o faringitis de repetición, con infecciones de frecuencia y severidad tal que lleguen a afectar seriamente la vida normal del niño. En todo caso, hay que individualizar el caso, conocer que el tamaño de las amígdalas se reduce a partir de los 6-8 años, recordar que a medida 
que el niño crezca se irá reduciendo el número de episodios y recordar que no se ha demostrado concluyentemente que la extirpación de las amígdalas reduzca el número de ataques a largo plazo, dificultando, en cambio, el diagnóstico (i Brú, 2017, pag. 391).

Muchas enfermedades tienen manifestaciones bucales primarias por sí mismas que permiten establecer el diagnóstico diferencial con otras enfermedades. En ocasiones los tratamientos médicos producen manifestaciones bucales secundarias. El diagnóstico oportuno de las manifestaciones bucales ayuda al tratamiento médico del paciente, que no hay que suspender por complicaciones debidas a estas manifestaciones. (De la Teja-Ángeles, Durán-Gutiérrez, Espinosa-Victoria, \& Ramírez-Mayans, 2008, pag. 189). Entre estas manifestaciones se encuentra, Neumonía bacteriana, neumonía no especificada, neumonía viral, Bronconeumonias. Rinitis alérgica, asma, sinusitis crónica, rinofaringitis aguda

Estamos, por tanto, ante una realidad que influye de forma decisiva en la salud diaria de los niños, en el gasto sanitario, en la aparición de resistencias a antibióticos y, por ende, en las decisiones que el pediatra ha de tomar diariamente. Dado que los estudios en nuestro ámbito son escasos, parece pertinente realizar un estudio prospectivo multicéntrico analizando diversas variables de respuesta (del Castillo Aguas, y otros, 2009, pag. 697)

\section{Bibliografia.}

Álvarez Castelló, M., Castro Almarales, R., Abdo Rodríguez, A., Orta Hernández, S., Gómez Martínez, M., \& Álvarez Castelló, M. (2008). Infecciones respiratorias altas recurrentes: Algunas consideraciones. Revista Cubana de Medicina General Integral, 24(1), 0-0.

Barcelos Arellane, R. L., \& Barrios Zaragoza, Y. (2014). FACTORES RELACIONADOS CON RINOFARINGITIS EN MENORES DE 5 AÑOS, DE LA CONSULTA EXTERNA. Poza Rica, Veracruz.

Benito Cabrera, M. (11 de 03 de 2016). bekiapadres. Obtenido de https://www.bekiapadres.com/articulos/faringitis-sintomas-tratamiento-ninos/ 
Cuestas, G., Losano, T., Zambrano, L., Ferraz, R., D’Aquila, M., \& Rodríguez, H. (2014). Complicaciones de las faringitis bacterianas. Faso.

De la Teja-Ángeles, E., Durán-Gutiérrez, A., Espinosa-Victoria, L., \& Ramírez-Mayans, J. (2008). Manifestaciones estomatológicas de los trastornos sistémicos más frecuentes en el Instituto Nacional de Pediatría. Revisión de la literatura y estadísticas del instituto. Acta Pediátrica de México, 29(4), 189-1999.

del Castillo Aguas, G., Iborra, A., Albarrán, J., Olid, M., Muñoz, G., Tallón, R., \& González, O. (2009). Influencia de la asistencia a las guarderías sobre la morbilidad y el consumo de recursos sanitarios en niños menores de 2 años. Pediatría Atención Primaria, 11(44), 695708.

Gómez, F., \& Valente, M. (s.f.). Incidencia de Infecciones Respiratorias Agudas en niños del centro de salud escuela Profesor Samuel B. Pessoa. São Paulo Brasil.

i Brú, J. (2017). Infecciones de vías respiratorias altas-1:faringitis aguda y recurrente. PediatríaIntegral.

Mora, G., \& Cristina, G. (2012). Efectividad de la Homeopatía unicista como coadyuvante en el tratamiento del resfriado común, sus complicaciones y recurrencias, en niños de 6 meses a 5 años en el jardín infantil de la Universidad Nacional de Colombia 2009-2011.

Rodríguez, S. U., Caicedo, A., \& Garcia, G. (2009). Guías de pediatría práctica basadas en la evidencia. Editorial Médica Panamericana.

Zabala Haro, A. M. (2010). Incidencia de las Enfermedades Respiratorias Agudas en Niños Menoresde Cinco Años, Atendidos en el Servicio de Consulta Externa de Pediatría del Hospital Provincial General de Latacunga entre Enero-Diciembre del 2008. Provincial General de Latacunga. 